\title{
THE EFFECT OF OSMIUM TETROXIDE AND NITROGEN MUSTARD ON NORMAL ARTICULAR CARTILAGE
}

\author{
Nelson Mitchell, Carroll laurin* and Nora Shepard, Montreal, Canada \\ From the Orthopaedic Research Laboratories of the Royal Victoria Hospital and \\ * The University of Montreal
}

In 1951 von Reis and Swensson reported their experience with intra-articular injections of osmic acid in man and animals. Clinical improvement was noted in thirty-five patients with painful joints, and the animal studies demonstrated widespread necrosis of synovium, which subsequently regenerated as shown by histological studies. They found no adverse effect on the articular cartilage either grossly or histologically and recommended the use of osmic acid in circumstances in which synovectomy might otherwise be considered. Other authors (Hurri, Sievers and Oka 1963; Berglöf 1964; Oka, Rekonen and Ruotsi 1969; Amini, Gagnon and Laurin, unpublished) have reported similar findings and in each instance, while the osmium caused synovial necrosis, little or no cartilage damage was reported.

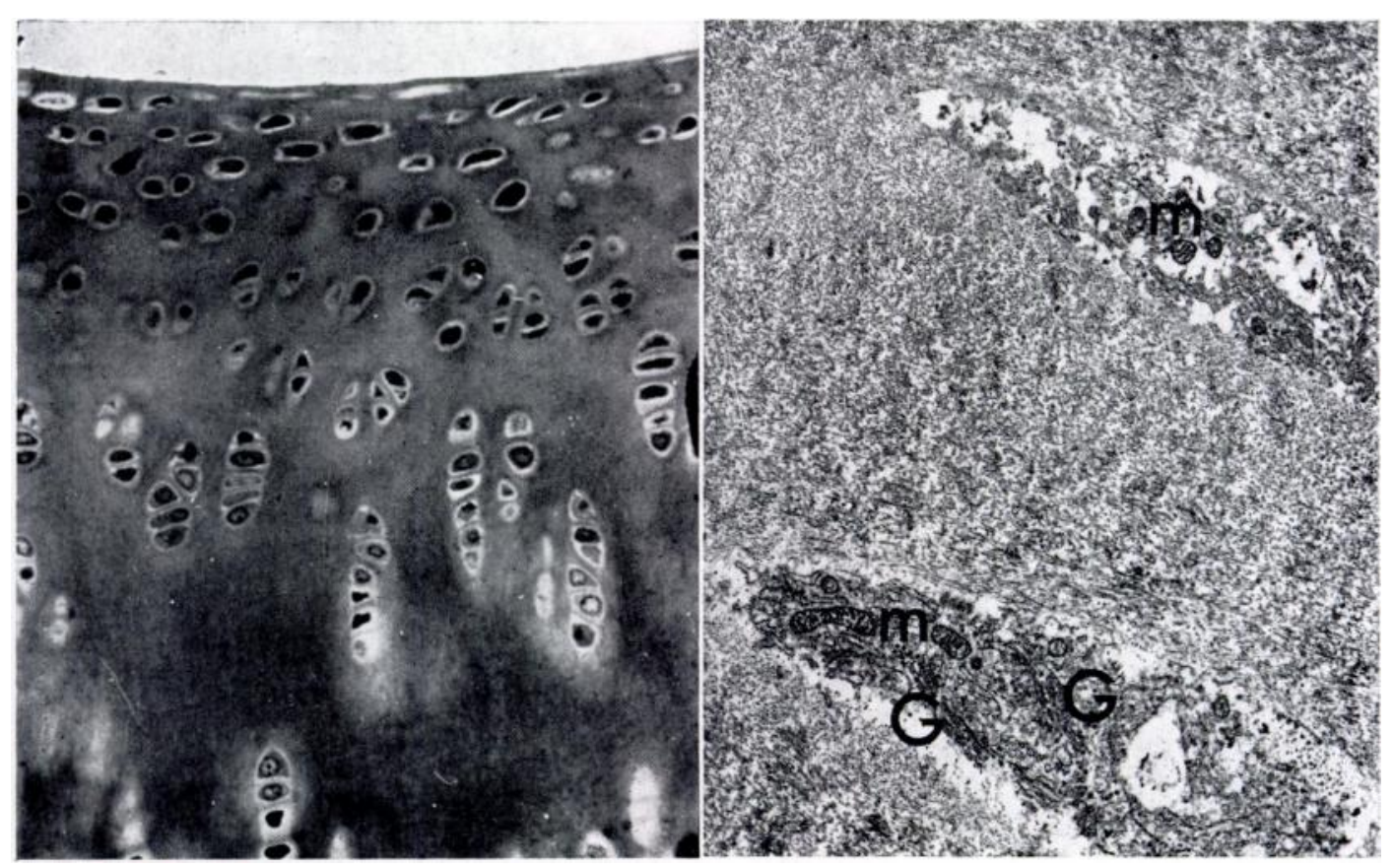

Fig. 1

FIG. 2

Figure 1-Articular cartilage four days after injection of osmic acid into the knee joint. $(\times 375$.) Figure 2 Chondrocytes from the uppermost third four days after injection with osmic acid. The cell membrane and cytoplasm have disintegrated though some of the mitochondria $(\mathrm{m})$ and Golgi $(\mathrm{G})$ persist, presumably fixed by osmium. $(\times 7,700$. $)$

Scherbel, Schuchter and Weyman (1957) recommended the use of intra-articular nitrogen mustard to effect a chemical synovectomy. They carried out animal and human studies and they, too, were able to produce chemical synovectomy without causing cartilage damage.

Since these reports both of these agents have been used widely in Europe and North America as a substitute for synovectomy in rheumatoid arthritis and related disorders 


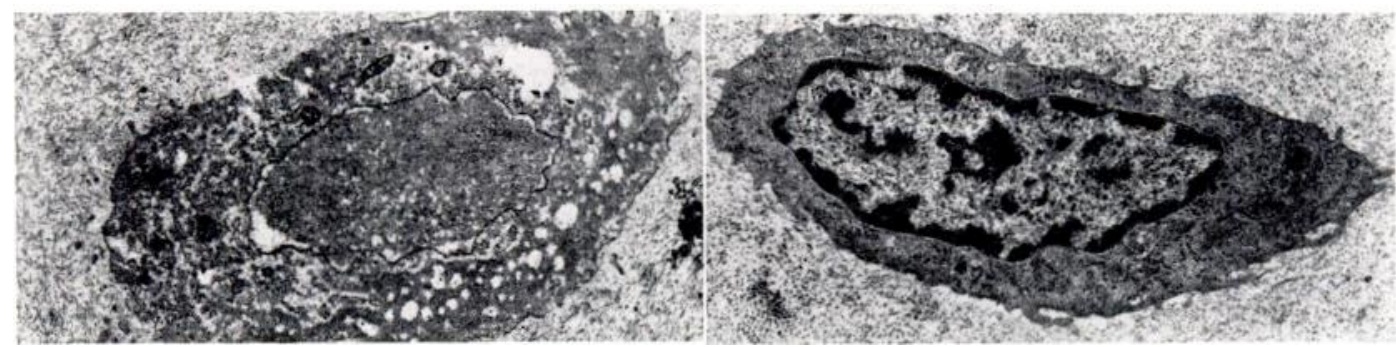

Fig. 3

Fig. 4

Figure 3-Part of a chondrocyte from the middle third at four days. Cell and nuclear disintę̧ration are again noted. $(\times 6,200$.) Figure 4-A normal chondrocyte from the uppermost third of the articular cartilage of a control joint. $(\times 3,600$.

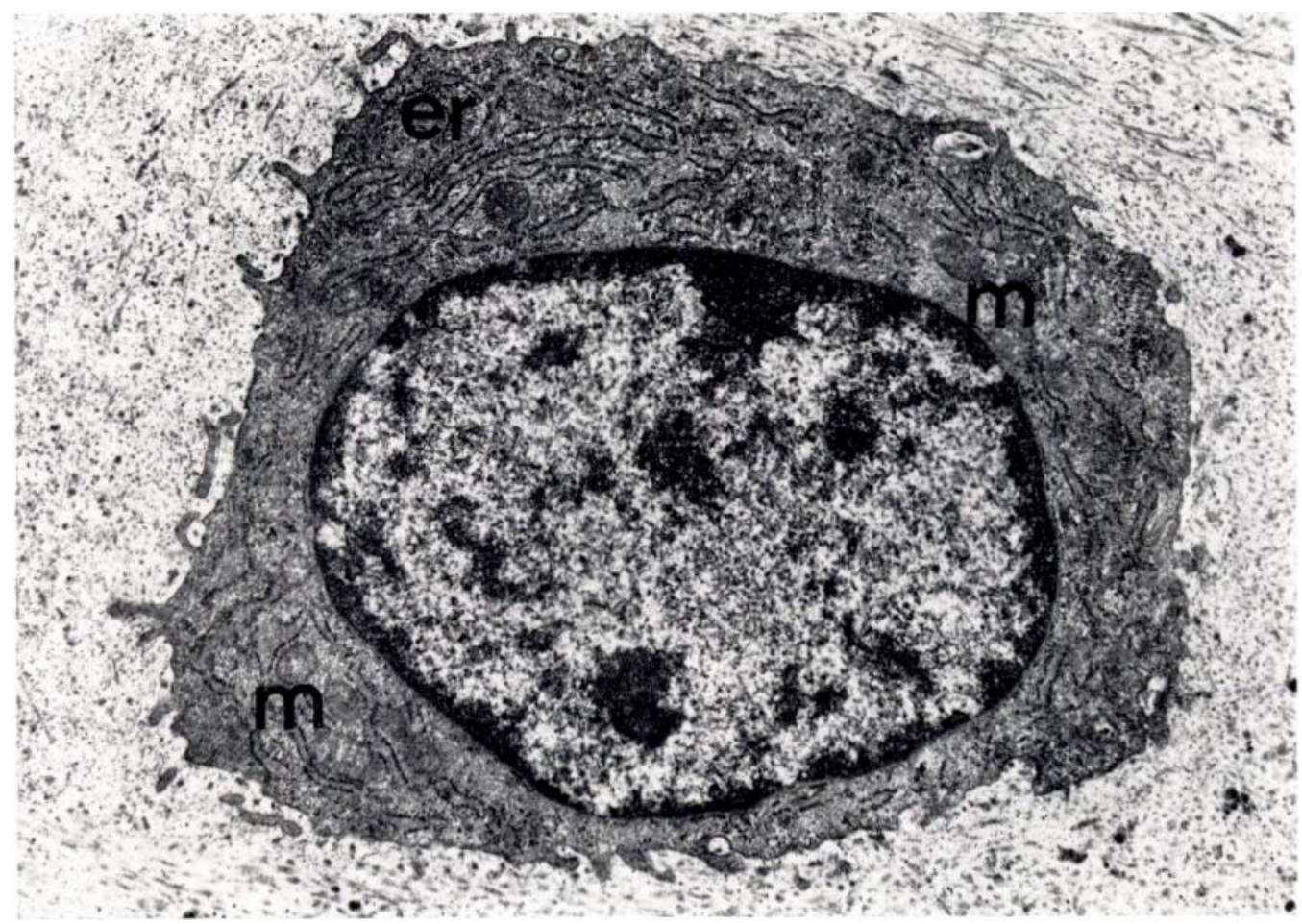

Fig. 5

A normal chondrocyte from the middle third of the articular cartilage. Mitochondria $(\mathrm{m})$ and abundant encoplasmic reticulum $(\mathrm{er})$ are seen. $(\times 13,000$.)

(Scherbel, Schuchter and Harrison 1957; Vainio and Julkunen 1960; Hurri, Sievers and Oka 1963; Berglöf 1964; Campbell and Berry 1965; Amini, Gagnon and Laurin unpublished). Because doubts that cartilage could resist the toxic effect of agents that cause such widespread necrosis of synovium this study was done.

\section{MATERIALS AND METHODS}

Thirty-eight knee joints in twenty adult rabbits were injected with 1 millilitre of 1 per cent osmium tetroxide, and twenty-eight knee joints in seventeen adult rabbits were injected with 1 milligram per kilogram of nitrogen mustard on two successive days. The nitrogen mustard was given in divided dosages to avoid the generalised toxic effects and the total dose amounted to approximately 0.8 milligram per animal, which was the average used by Scherbel, Schuchter

VOL. 55 B, NO. 4, NOVEMBER 1973 


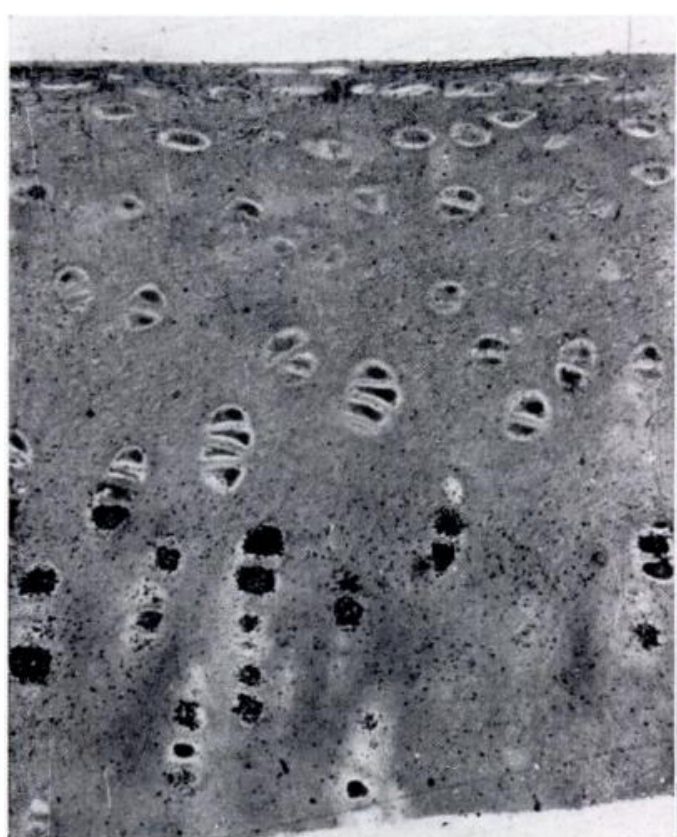

Fig. 6

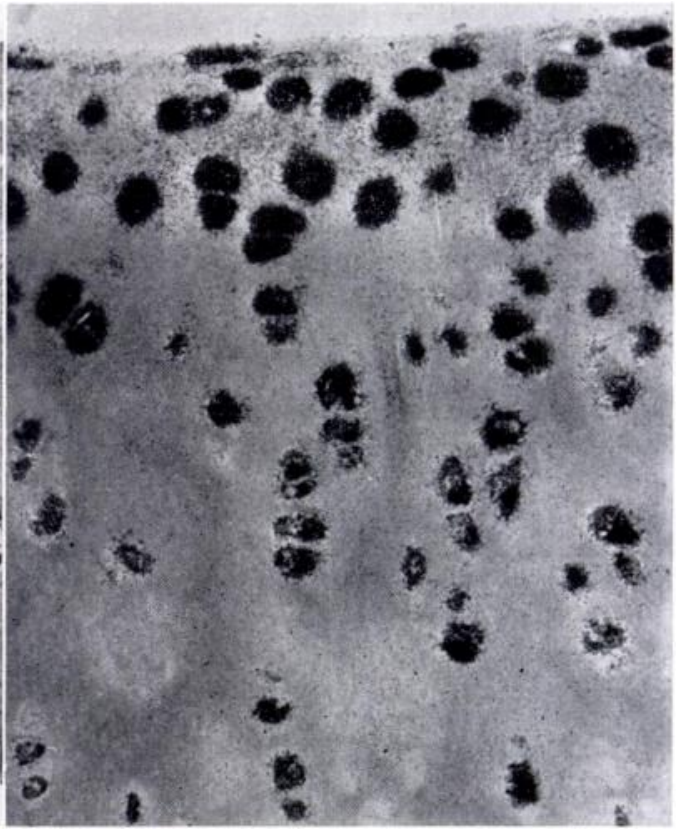

FIG. 7

Figure 6-Autoradiograph four days after osmium showing proline uptake by the deep chondrocytes only. $(\times 375$.$) Figure 7$-Control cartilage showing abundant proline uptake. $(400$.

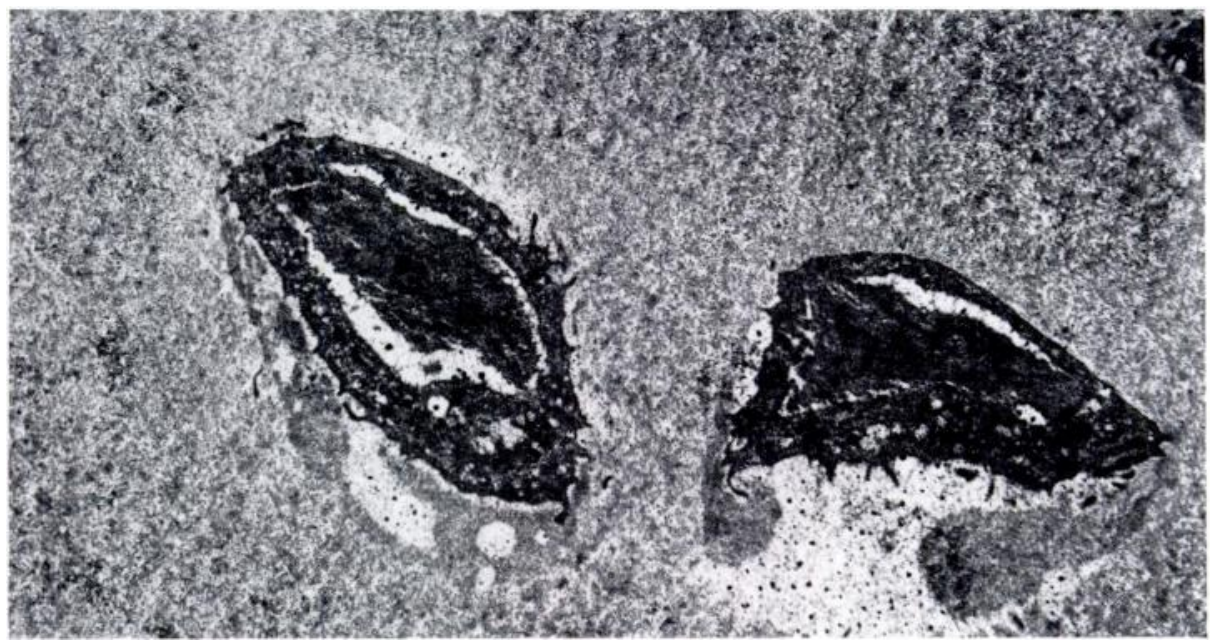

Fig. 8

Chondrocytes from the upper third of the cartilage four months after osmic acid. The chondrocytes are dead but the matrix and cell surface remain intact. $(\times 9,500$.)

and Weyman (1957). Control joints consisted of the remaining uninjected joints of these rabbits and a group of ten rabbits of the same age and sex which were designated as control animals at the beginning of the experiment and segregated accordingly.

Animals were killed at intervals from three days to seven months after injection and the cartilage was inspected. The joints were then removed and sections of articular cartilage were prepared for light and electron microscopy. Some portions of cartilage were incubated for four hours in a Krebs-Ringer bicarbonate solution containing $3 \mathrm{H}$ proline $100 \mu \mathrm{Ci} /$ millilitre and these sections were later prepared to yield light and electron microscopic autoradiographs in order to assess further the viability of the articular chondrocytes. 


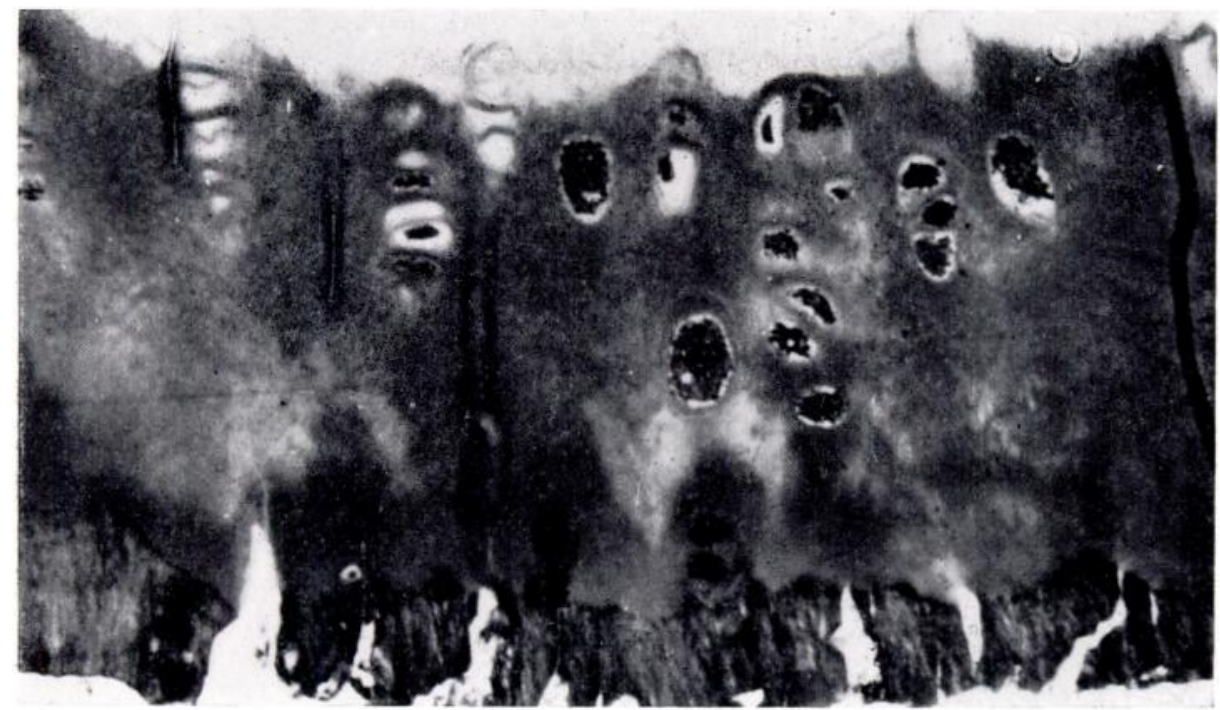

FIG. 9

Seven months after injection with osmium the lowest third of the cartilage matrix remains. $(\times 624$. $)$

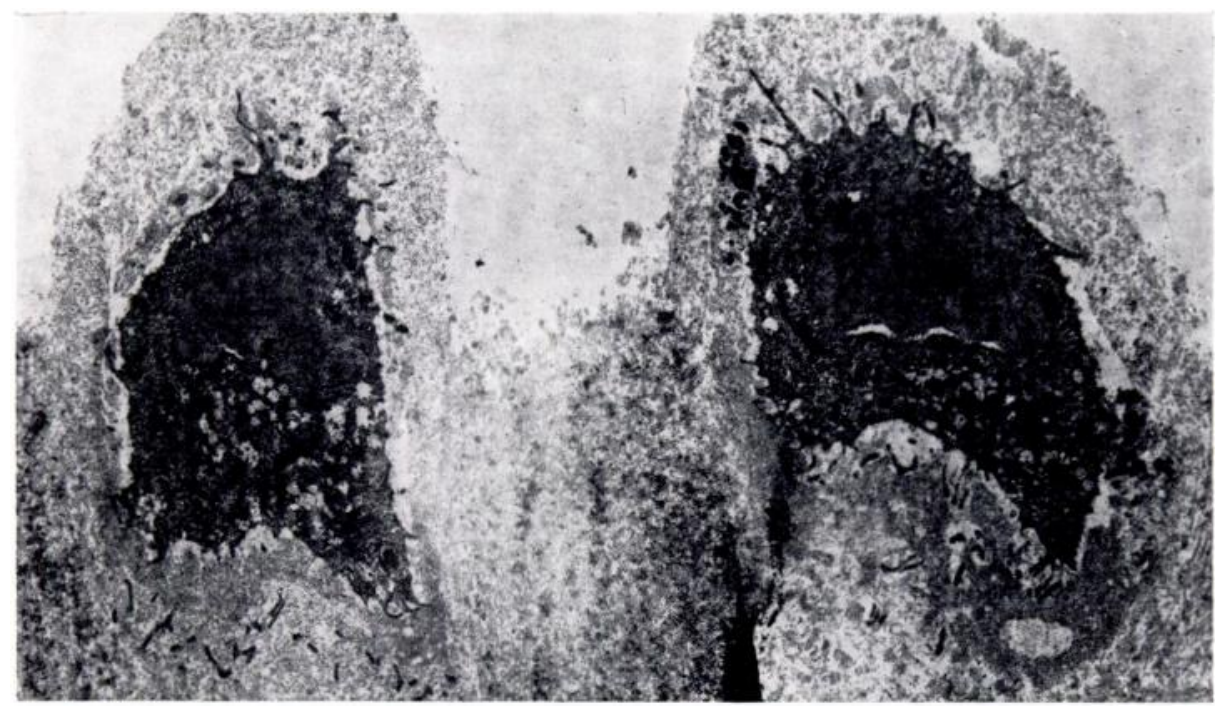

Fig. 10

Seven months after osmium the dead chondrocytes are being extruded into the joint cavity. $(\times 6,660$.

\section{RESULTS}

Osmium tetroxide-At four days the cartilage appeared normal both grossly and by light microscopy (Fig. 1). Electron microscopy, however, showed disintegration and death of cells in the upper and middle thirds of the cartilage (Figs. 2 and 3). Although some of the organelles, notably mitochondria and Golgi zones, were preserved the cell membranes and general intracellular structures were completely absent. Normal chondrocytes from control joints are shown in Figures 4 and 5.

Proline uptake autoradiographs showed no grains over the cells in the upper layers and uptake was noted over the deepest cells only (Fig. 6). Control autoradiographs are shown in Figure 7. Four months after injection the surface of the cartilage still appeared intact although the dead chondrocytes persisted (Fig. 8). Seven months after injection the cartilage 


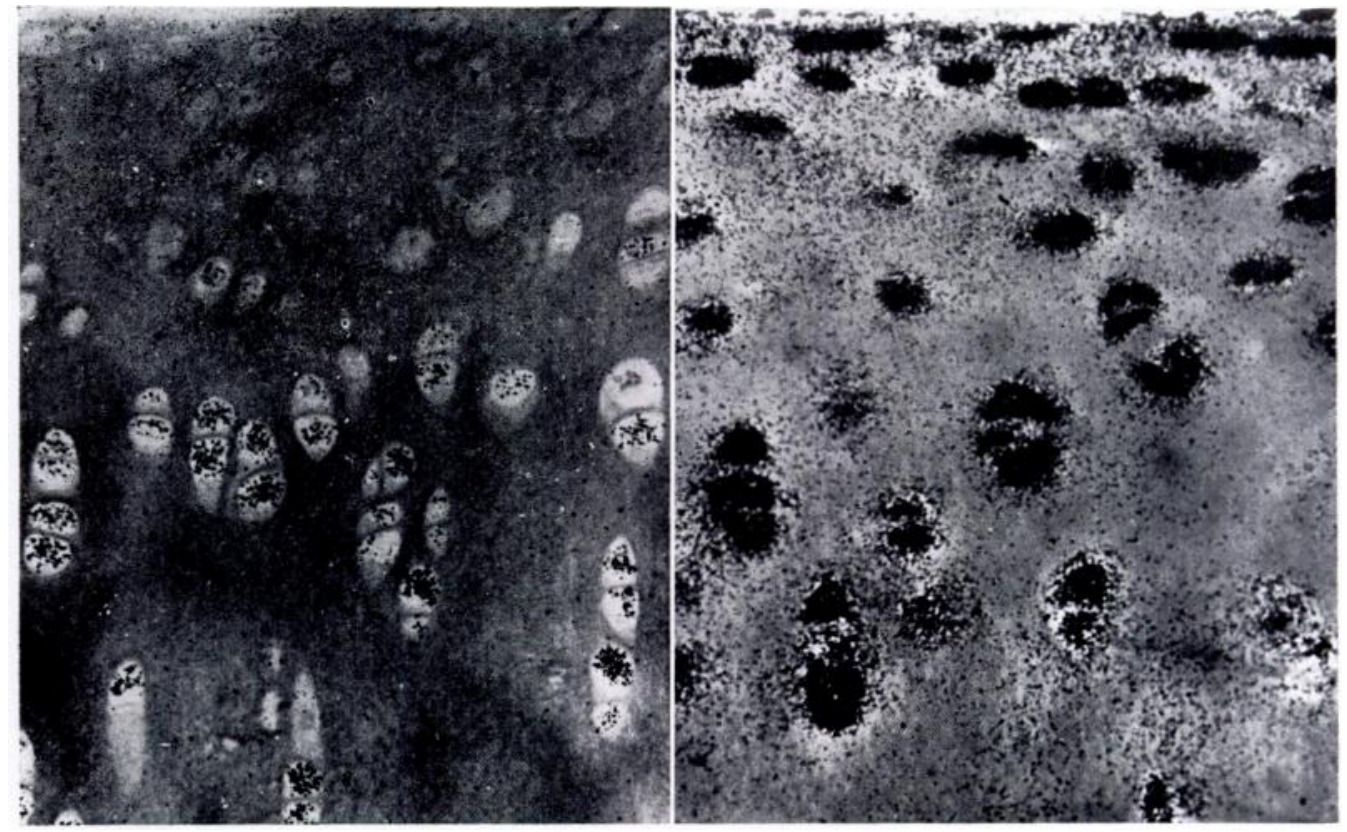

Fig. 11

FIG. 12

Figure 11-Autoradiograph of articular cartilage one week after nitrogen mustard. Only a few grains were noted over the deeper cells. $(\times 425$.) Figure 12 - Control cartilage showing abundant uptake over cells of all layers. $(\times 400$. $)$

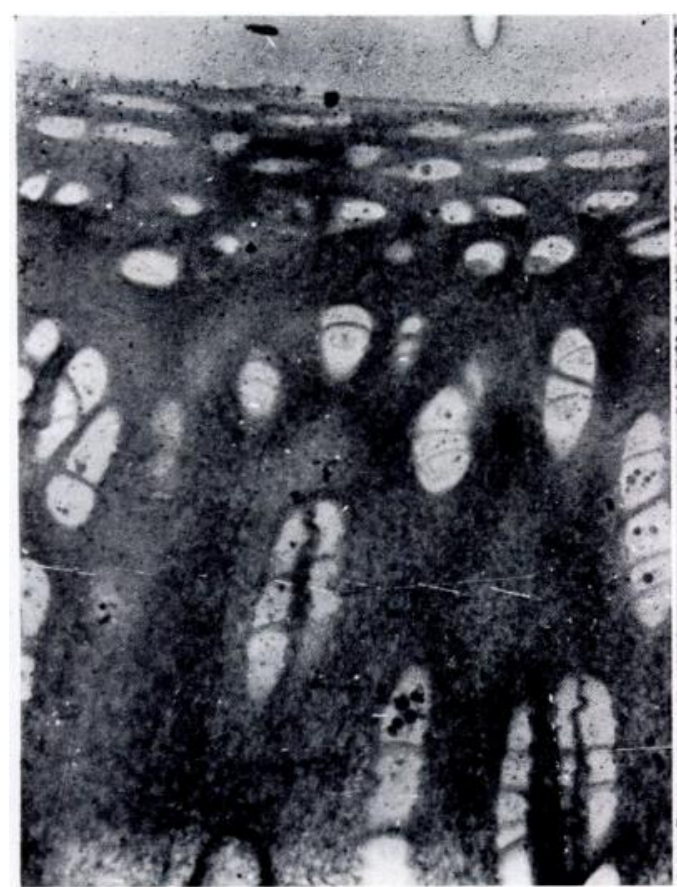

FIG. 13

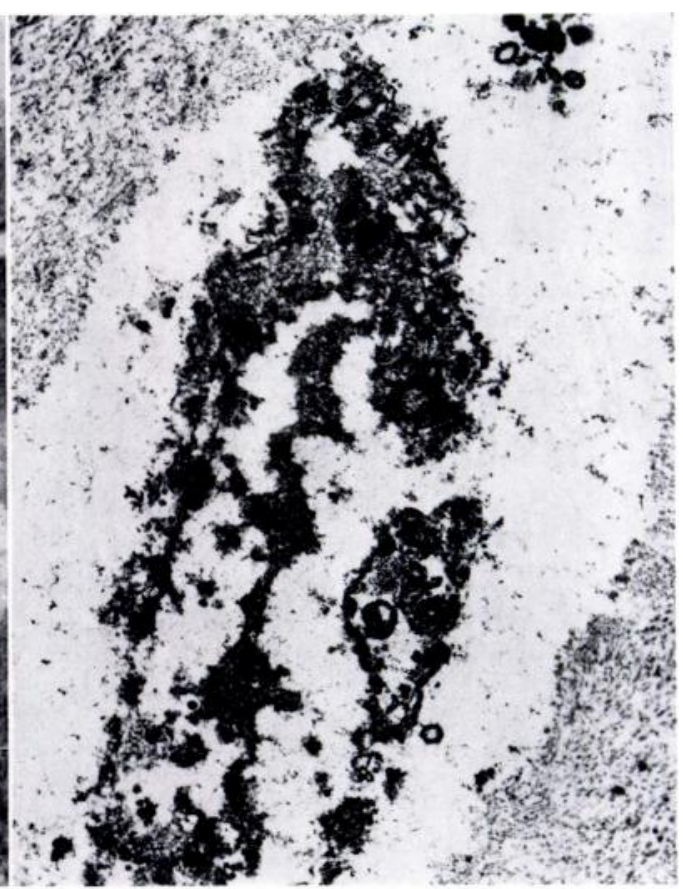

Fig. 14

Figure 13-An autoradiograph one month after injection of nitrogen mustard. The chondrocytes have accumulated considerable amounts of lipid, although no grains were seen over the cells. $(\times 400$.) Figure 14 A surface chondrocyte one month after nitrogen mustard. Cell disintegration can be seen. $(\times 15,875$. $)$ 
matrix began to disintegrate and dead cells began to be extruded into the joint (Figs. 9 and 10). Nitrogen mustard-One week after injection of nitrogen mustard the deeper chondrocytes were still able to take up small amounts of radioactive proline (Fig. 11). This uptake was much less than that seen in the controls (Fig. 12). The articular cartilage had accumulations of lipid in the upper layers and the autoradiographs demonstrated widespread cell death (Fig. 13). Electron microscopy showed disintegration of cell cytoplasm in all zones (Figs. 14 and 15).

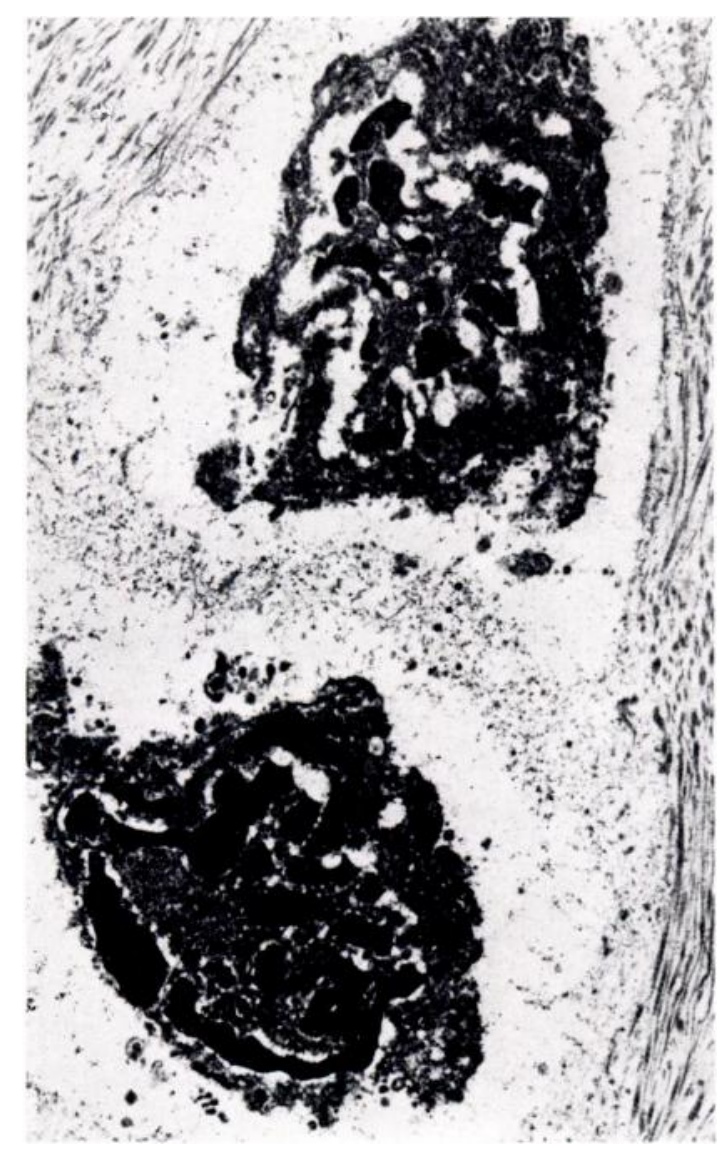

FIG. 15

Chondrocytes from the mid zone of the same joint as Figure 14 showing cell death. $(\times 10,115$.)

Two months after injection only slight irregularity appeared in the articular cartilage when viewed macroscopically at necropsy (Fig. 16). Examination of the cartilage at this time by electron microscopy showed cell remnants, lipid and debris (Fig. 17). Three to five months after injection only a thin remnant of the articular cartilage remained (Fig. 18), and at seven months the joint was grossly abnormal with total loss of articular cartilage and some bony osteophytes at the margins (Fig. 19).

\section{DISCUSSION}

Osmium tetroxide and nitrogen mustard when injected intra-articularly into animal joints caused early and extensive chondrocyte necrosis. Such cartilage cell necrosis was not apparent initially when viewed through the light microscope alone. Electron microscopy and labelled matrix precursor uptake studies, such as radioactive proline autoradiographs, however, verified the death of chondrocytes. It appears that because of the mechanical properties of the cartilage matrix and the relatively few cells present, death of chondrocytes did not

VOL. 55 B, NO. 4, NOVEMBER 1973 


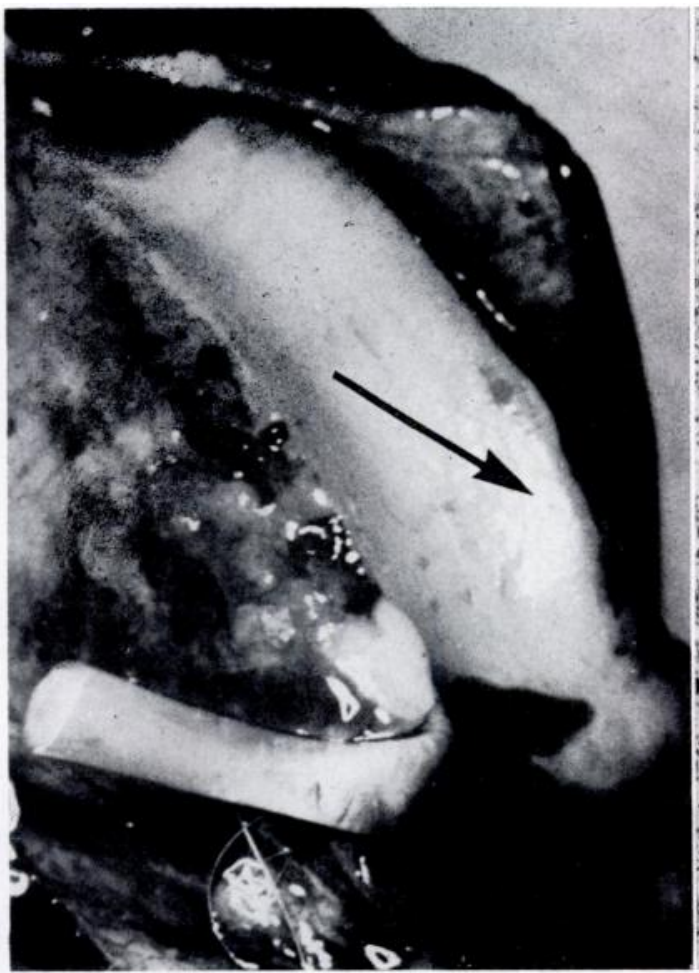

FIG. 16

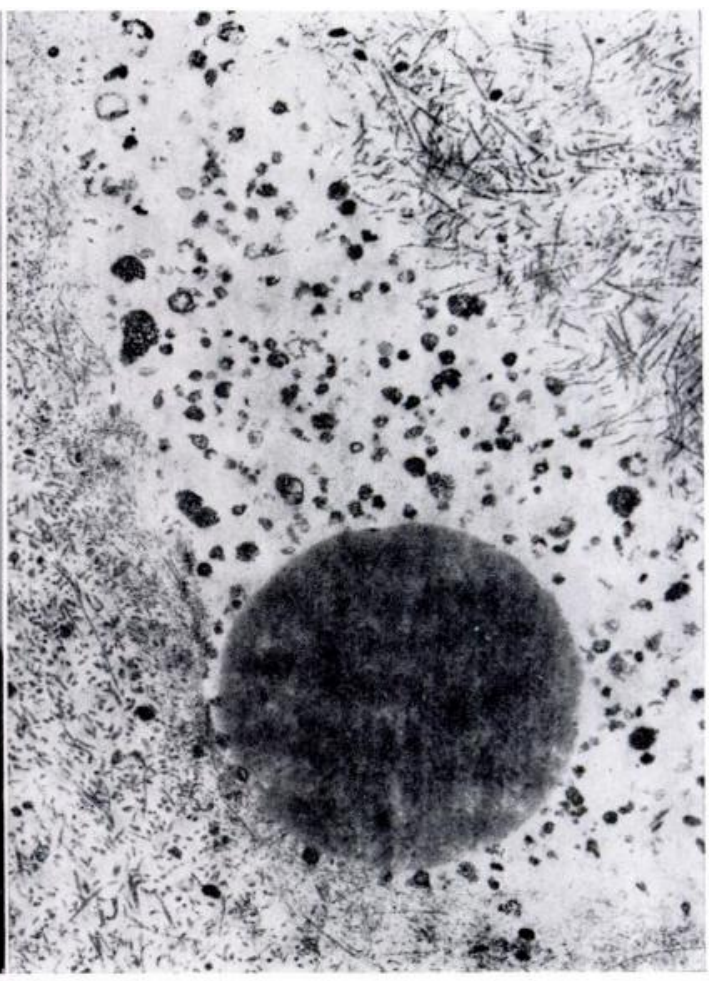

FIG. 17

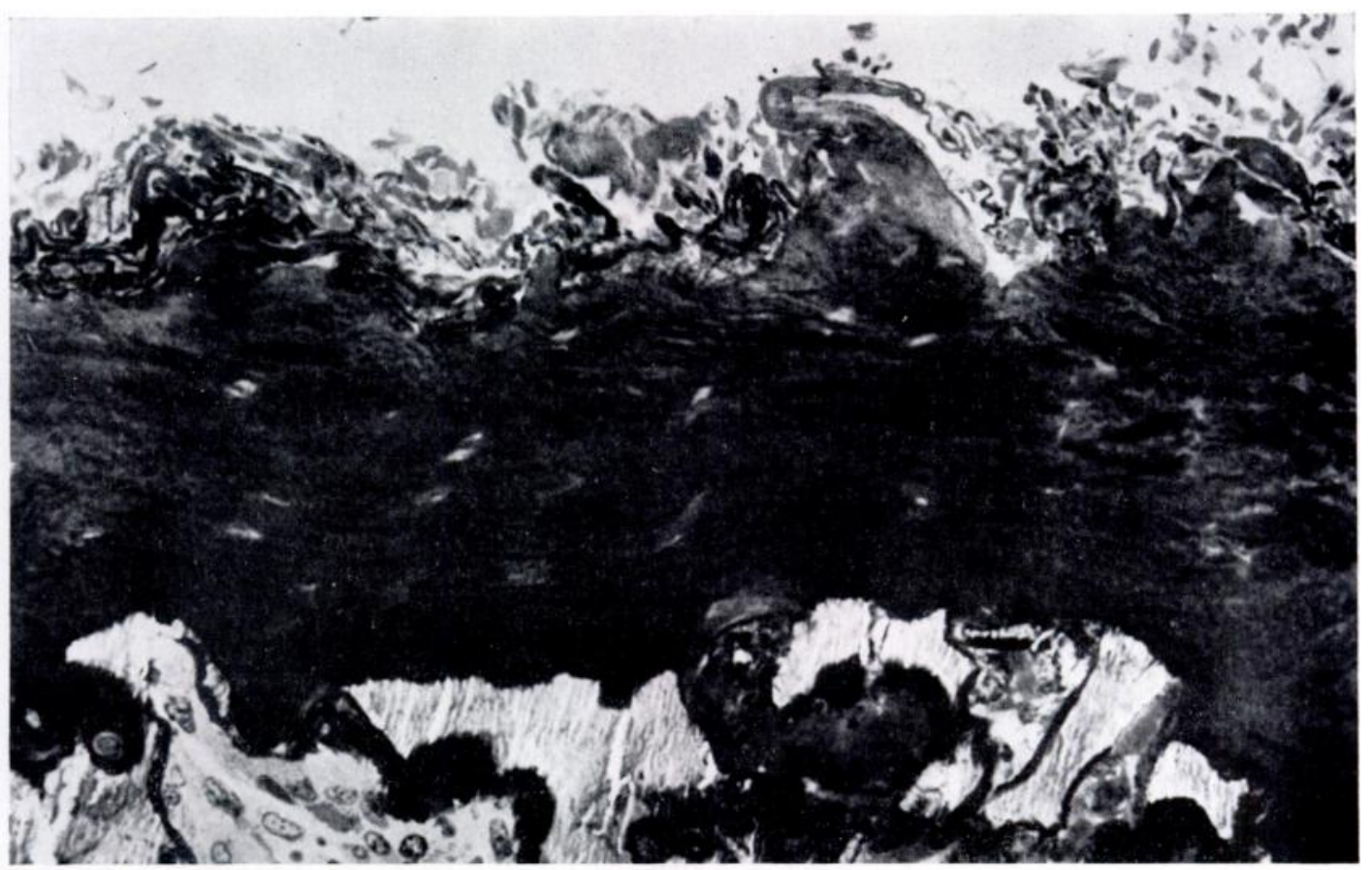

FIG. 18

Figure 16-At death two months after injection the cartilage surface showed only slight irregularity (arrow). Figure 17-Two months after nitrogen mustard the chondrocyte lacunae contained only lipid and other cellular debris. $(\times 7,750$.) Figure 18-Articular cartilage removed from a joint four months after nitrogen mustard. $(\times 565$. 
immediately result in disintegration of the cartilage. This required some time to become apparent. It is perhaps for this reason that clinical studies and other animal studies in which the animals were observed for only a short time, may not have shown the degree of cartilage destruction which ultimately ensued after the use of these intra-articular agents in animals.

The search for a suitable agent for chemical synovectomy continues, and although an agent may well be found capable of destroying synovium without inflicting damage on articular cartilage, the results of this study suggest that joints will have to be followed for several months or studied with more elaborate tools than light microscopy to be sure that the agent is not causing cartilage necrosis.

\section{SUMMARY}

1. Osmium tetroxide and nitrogen mustard were injected into normal adult rabbit joints. Within one week widespread chondrocyte necrosis had occurred as evidenced by electron microscopic examination and radioactive proline uptake autoradiography.

2. Initially, the cartilage matrix was intact but three to seven months later the cartilage

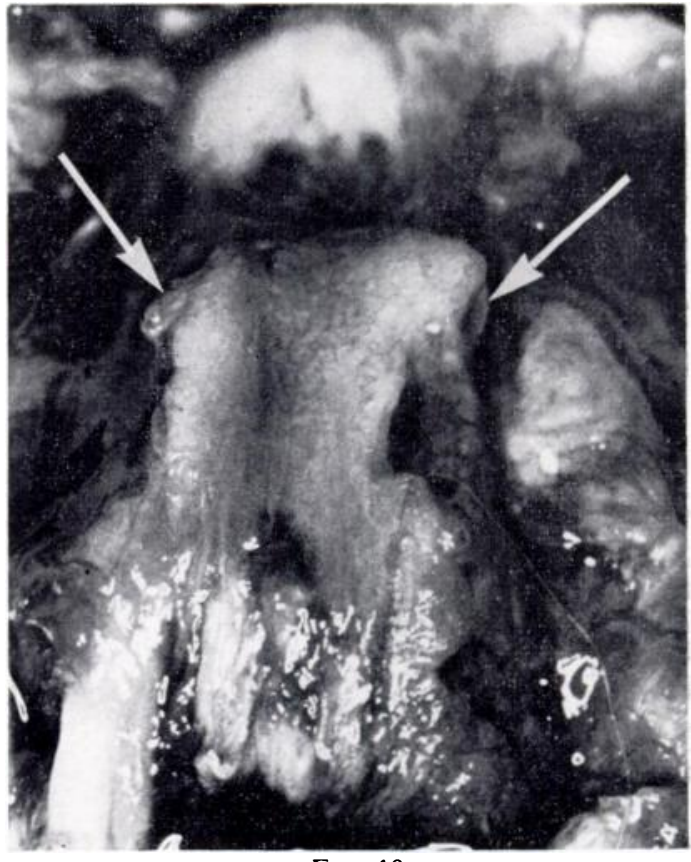

FIG. 19

The knee joint from an animal seven months after nitrogen mustard. The cartilage is completely absent and osteophytes have formed at the margins of the joint (arrows). surface began to disintegrate.

3. These studies indicate that osmium tetroxide and nitrogen mustard are unsuitable agents for chemical synovectomy.

4. They also indicate that there may be a long latent period between cartilage cell death and cartilage destruction, and that the evaluation of any agent for chemical synovectomy must take this into consideration.

This project was supported by a grant from the Medical Research Council of Canada.

\section{REFERENCES}

Berglöf, F.-E. (1964): Further Studies on the Use of Osmic Acid in the Treatment of Arthritis. Actur rheumatologica Scandinatica, 10, 92.

Campbell, W. G., Jun., and Berry, S. R. (1965): Lesions in Subsynovial Tissue. Archives of Patholog!r 79.7.

Hurri, L., Sievers, K., and OKa, M. (1963): Intra-articular Osmic Acid in Rheumatoid Arthritis. Actor rheumatologica Scandinavica, 9, 20.

Oka, M., Rekonen, A., and Ruotsi, A. (1969): The Fate and Distribution of Intra-articularly Injected Osmium Tetroxide (Os-191). Acta rheumatologica Scandinavica, 15, 35.

Rfis, G. von, and Swensson, $\AA$. (1951): Intra-articular Injections of Osmic Acid in Painful Joint Affections. Acta medica Scandinavica, Supplementum 259, 27.

Schirbel, A. L., Schuchter, S. L., and Harrison, J. W. (1957): A Rational Approach to the Treatment of Rheumatoid Arthritis. V. Chemotherapy in Rheumatoid Arthritis: A Concept. Cleveland Clinic Quarter/!. 24, 105.

Scherbel, A. L., Schuchter, S. L., and Weyman, S. J. (1957): A Rational Approach to the Treatment of Rheumatoid Arthritis. II. Intra Articular Administration of Nitrogen Mustard Alone and Combined with a Corticosteroid for Rheumatoid Arthritis. Cleveland Clinic Quarterly, 24, 78.

VAinio, J., and Julkunen, H. (1960): Intra-articular Nitrogen Mustard Treatment of Rheumatoid Arthritis. Acta rheumatologica Scandinavica, 6, 25.

VOL. 55 B, NO. 4, NOVEMBER 1973 